\title{
GLUT1 Regulation of the Pro-Sclerotic Mediators of Diabetic Nephropathy
}

\author{
Charles W. Heiliga Dilip K. Deb ${ }^{b}$ Afu Abdulc Hasan Riaz ${ }^{a}$ Leighton R. James ${ }^{a}$ \\ Jamal Salameh $^{\mathrm{a}}$ N. Stanley Nahman Jr. ${ }^{\mathrm{c}}$ \\ aDepartment of Medicine, University of Florida College of Medicine - Jacksonville, Jacksonville, Fla., \\ ${ }^{b}$ Department of Medicine, University of Chicago Pritzker School of Medicine, Chicago, III., and \\ 'Department of Medicine, Georgia Regents University and Charlie Norwood VAMC, Augusta, Ga., USA
}

\section{Key Words}

GLUT1 · Diabetic nephropathy · Glomerulosclerosis .

Glucose transporter · Growth factors · Vascular endothelial growth factor

\begin{abstract}
Diabetic glomerulosclerosis is characterized by accumulation of extracellular matrix proteins, mesangial expansion, and tubulointerstitial fibrosis. Hyperglycemia accelerates development of the disease, a direct result of increased intracellular glucose availability. The facilitative glucose transporter GLUT1 mediates mesangial cell glucose flux which leads to activation of signaling cascades favoring glomerulosclerosis, including pathways mediated by angiotensin II (Ang II), transforming growth factor $\beta$ (TGF- $\beta$ ), connective tissue growth factor (CTGF), and vascular endothelial growth factor (VEGF). Ang II has both hemodynamic and metabolic effects directly inducing GLUT1 and/or matrix protein synthesis through diacyl glycerol (DAG) or protein kinase $C$ (PKC) induction, mesangial cell stretch, and/or through transactivation of the epidermal growth factor receptor, the platelet-derived growth factor receptor, and the insulin-like growth factor-1 receptor, all of which may stimulate GLUT1 synthesis via an ERK-mediated pathway. Conversely, inhibi-
\end{abstract}

tion of Ang II effects suppresses GLUT1 and cellular glucose uptake. GLUT1-mediated glucose flux leads to metabolism of glucose via glycolysis, with induction of DAG, PKC, TGF- $\beta_{1}$, CTGF and VEGF. VEGF in turn triggers both GLUT1 and matrix synthesis. New roles for GLUT1-mTOR and GLUT1-mechanogrowth factor interactions in diabetic glomerulosclerosis have also recently been suggested. Recent mouse models confirmed roles for GLUT1 in vivo in stimulating glomerular growth factor expression, growth factor receptors and development of glomerulosclerosis. GLUT1 may therefore act in concert with cytokines and growth factors to induce diabetic glomerulosclerosis. Further clarification of the pathways involved may prove useful for the therapy of diabetic nephropathy. New directions for investigation are discussed.

Copyright $\odot 2013$ S. Karger AG, Basel

\section{Introduction}

Diabetic nephropathy is the leading cause of end-stage kidney failure in the United States [1]. The disease is characterized by the accumulation of extracellular matrix protein in the mesangial space with mesangial expansion, thickening of the glomerular and tubular basement membranes, and tubulointerstitial fibrosis $[2,3]$.

\section{KARGER}

E-Mail karger@karger.com

www.karger.com/ajn
(C) 2013 S. Karger AG, Basel

0250-8095/13/0381-0039\$38.00/0 
The exact pathogenesis of diabetic nephropathy is unknown; however, hyperglycemia has been shown to accelerate the development of clinical nephropathy in the Diabetes Control and Complications Trial (DCCT) $[4,5]$. In this regard, the DCCT and the United Kingdom Prospective Diabetes Study (UKPDS) demonstrated a clear link between hyperglycemia and the development of microvascular complications $[4,5]$. In addition, the treatment of diabetics with pancreatic transplantation and normalization of serum glucose levels has been associated with regression of diabetic glomerular disease [6].

Hyperglycemia has also been shown to drive the production or expression of many factors associated with the development of diabetic nephropathy, including angiotensin II (Ang II), transforming growth factor $\beta$ (TGF- $\beta$ ), connective tissue growth factor (CTGF) and vascular endothelial growth factor (VEGF) [7]. This suggests that increased intracellular glucose availability may represent an important proximal stimulus in the development of fibrosis by activating these mediators.

At the cellular level, hyperglycemia generates incessant metabolic pressure for the activation of glucose-dependent biochemical and enzymatic pathways. In the kidney, the facilitative glucose transporter GLUT1 is a primary gatekeeper of this process by regulating glucose movement into the cell. Furthermore, in the glomerular mesangial cell the expression of GLUT1 is the rate-limiting step for glucose flux and utilization [8]. At the level of the organism, all of the above processes are highly integrated. To address these events in vivo, several novel transgenic mouse models have helped to advance our understanding of the role of GLUT1 in the development of glomerulosclerosis and nephropathy [9-11].

GLUT1-facilitated transport of glucose results in the activation of signaling cascades favoring glomerulosclerosis $[8,10-12]$. Thus, GLUT1 activity may be a regulator of the development of fibrosis in this disease. In support of this contention, mesangial cells overexpressing GLUT1 and cultured in normal glucose exhibit a diabetic phenotype with an increase in matrix protein synthesis [8]. In addition, transgenic mice overexpressing GLUT1 develop diabetic glomerulosclerosis and nephropathy despite normoglycemia [10]. Conversely, overexpression of a GLUT1 antisense sequence prevented diabetic changes in mesangial cells cultured in high glucose [13], and in vivo, transgenic $\mathrm{db}$ mice expressing an antisense sequence to glomerular GLUT1 did not develop diabetic glomerulosclerosis despite hyperglycemia [14]. These data imply a regulatory role for GLUT1 in mediating the activation of pro-sclerotic events in diabetes, and suggest an addition- al active rather than a simple facilitative role of the transporter in this process.

The goal of this review is to assess the evidence supporting GLUT1 as a regulator of the cytokines and growth factors promoting diabetic glomerulosclerosis and nephropathy, and explore a new paradigm for GLUT1 in mediating the pathogenesis of this disease.

\section{Facilitative Glucose Transport by GLUT1 and Diabetic Nephropathy}

Enhanced cellular glucose uptake is mediated by the facilitative glucose transporter proteins (GLUT), part of a super family of SLC (solute carrier) genes [15]. At least 14 GLUT transporters have been identified and exhibit a broad distribution with tissue-specific regulation [15]. The GLUT proteins are hexose transporters with substrate specificity for glucose, fructose, and/or galactose [15]. Structurally, the GLUT proteins are thought to have 12 transmembrane domains, with an intracellular loop between domains 6 and 7, and, depending on the specific transporter, a long glycosylated extracellular loop between domains 1 and 2 or domains 9 and 10 [15]. The mechanisms by which the GLUT proteins transport their substrates are not fully defined, but it has been suggested that each transporter may have a form of selectivity filter at the entrance to the pore created by the protein [15].

In the glomerulus, GLUT1 and GLUT4 are the primary glucose transporters [16], with GLUT1 predominating in mesangial cells [17]. Under hyperglycemic conditions typical of the diabetic milieu, mesangial cell GLUT1 synthesis and expression is increased and is associated with enhanced glucose flux [18]. Similarly, overexpression of GLUT1 in mesangial cells cultured under normal glucose conditions mimics the diabetic state, and results in significant increases in both glucose uptake and utilization, as well as activation of matrix protein synthesis $[8,19]$. These responses were prevented when an antisense sequence to GLUT1 was overexpressed in mesangial cells cultured in high glucose [13]. Thus, GLUT1 expression is the rate-limiting step for the movement of glucose into the cell, regardless of the extracellular glucose concentration.

Increased GLUT1 expression stimulates glucose flux and utilization, and thus triggers all downstream responses associated with increases in glucose availability. Factors known to stimulate the GLUT1 gene include glucose, serum, growth factors, hypoxia and hyperosmolarity [20$23]$. The diverse number of activators of GLUT1 synthesis
Heilig/Deb/Abdul/Riaz/James/Salameh/ Nahman Jr. 
implies an important role for glucose flux and utilization from a variety of environmental stimuli, and suggests that GLUT1 may contribute to the regulation of glomerulosclerosis through these pro-sclerotic signaling pathways. Clinically, these events could have a direct effect on the pathogenesis of both diabetic and nondiabetic forms of glomerulosclerosis.

Recent developments highlighting a central role for GLUT1 in the development of mesangial matrix protein accumulation in glomerulosclerosis is further supported by three in vivo studies. First, overexpression of GLUT1 in nondiabetic C57BL6 mice resulted in the development of changes consistent with diabetic glomerulosclerosis [10], and suggests that an increase in GLUT1-mediated glucose flux is sufficient to drive pro-sclerotic pathways leading to diabetic glomerulosclerosis. Second, nondiabetic, nephron-deficient Fvb mice develop glomerulosclerosis in conjunction with increased GLUT1 synthesis and expression [10]. This work indicates that stimuli associated with reduced nephron mass, including glomerular hypertension with mesangial cell stretch, are sufficient to trigger increases in GLUT1 expression. Finally, it has been demonstrated in a preliminary report that mesangial mechano-growth factor (MGF), a splice variant of insulin-like growth factor-1 (IGF-1) involved in tissue repair and hypertrophy, is increased in glomeruli of diabetic mice and in nondiabetic GLUT1 - overexpressing transgenic mice [24], and is part of a GLUT1-MGF-positive feedback loop driving mesangial fibronectin synthesis [25]. In addition, recent data suggest a role for GLUT1induced $\mathrm{mTOR}$ in mesangial dysfunction and glomerular disease in diabetes [26]. In experiments where GLUT1 was overexpressed in mesangial cells in the absence of high extracellular glucose, glucose flux and mTOR activity were increased. Increased mTOR activity also leads to increased GLUT1 and glucose flux [26]. These data together suggested a feed-forward mechanism resulting in persistently increased GLUT1 and mTOR activity in diabetic glomeruli [26].

Taken together, these data provide compelling evidence for a direct role of GLUT1 in facilitating the development of both diabetic and nondiabetic forms of glomerulosclerosis and would suggest that GLUT1 may be an important proximal regulator in the development of this disease. To address this question in the context of diabetic glomerulosclerosis, the following sections will examine the interactions between GLUT1 and the cytokines and growth factors mediating the development of the disease, and seek to define the role of GLUT1 as a potential gatekeeper of the these pathologic pathways.

\section{Pro-Sclerotic Mediators of Diabetic Nephropathy and GLUT1}

\author{
Angiotensin II (fig. 1a)
}

Ang II is a vasoactive cytokine mediating its major effects via the AT1 receptor [27]. In the kidney, Ang II has both hemodynamic and metabolic effects [28, 29]. In diabetes, increased glucose availability may increase Ang II levels by stimulating synthesis [30] or through vasoactive responses to a reduction in glomerular filtration surface area [31].

The AT1 receptor is a G-protein-linked receptor interacting with several intracellular signal conduction pathways. Through G proteins, the AT1 may trigger second messengers including diacyl glycerol (DAG) and reactive oxygen species [27]. DAG is also a product of glucose metabolism and is known to stimulate gene transcription via the protein kinase $\mathrm{C}$ (PKC) activation pathway [32].

Ang II signaling pathways interact with GLUT1 at several levels, providing potential opportunities for GLUT1 to amplify the pro-sclerotic effects of Ang II. In this regard, DAG production leads to an increase in GLUT1 gene expression via PKC $[19,21]$. An increase in GLUT1 expression results in enhanced glucose flux and utilization, which triggers production of more DAG and additional PKC activation. The latter also includes stimulation of extracellular matrix protein synthesis and directly promotes the development of sclerosis [19, 33]. In this regard, mesangial cells overexpressing GLUT1 activate the PKC $\alpha$ and $P K C \beta 1$ isoforms with subsequent increases in the activating protein 1 (AP-1) transcription factor [34]. AP-1 binding to the fibronectin gene resulted in enhanced fibronectin synthesis [34].

Ang II has also been shown to trigger GLUT1 gene expression in association with epidermal growth factor receptor (EGFR) transactivation [35]. In this pathway, EGFR activation may lead to an induction of ERK [27], which has been shown to induce the GLUT1 gene and protein synthesis [36]. In mesangial cells, Ang II transactivation of platelet-derived growth factor receptor (PDGFR) and IGF-1 receptor (IGF-1R) may also represent additional stimuli to ERK activation [27].

The vasoactive effects of Ang II may stimulate GLUT1 synthesis [29]. In this regard, an increase in GLUT1 expression has been observed following mesangial cell stretch [11] and in conjunction with a nephron-deficient mouse model with glomerular hypertension and hyperperfusion $[11,37]$ and in Milan normotensive rats [38, 39], all of which would be an expected result of Ang II vasoactivity [40]. Furthermore, in 2010, Wang et al. [11] 



1

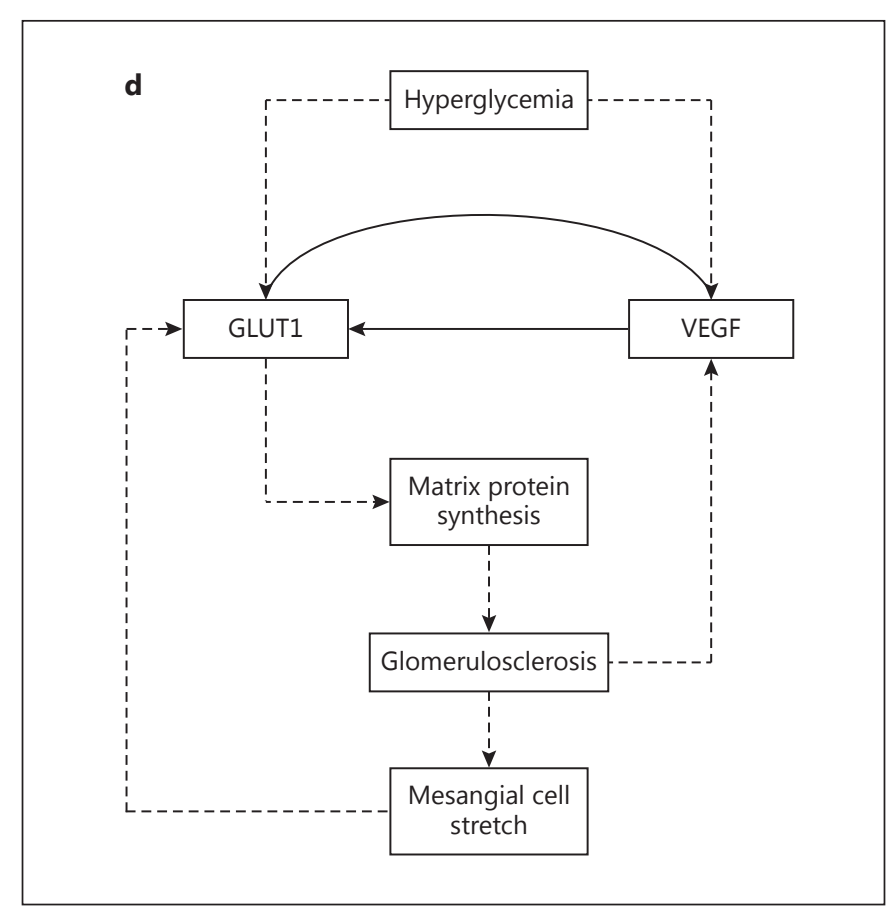

linked GLUT1 expression and mesangial cell stretch to VEGF production and an associated increase in matrix protein synthesis, providing an additional conduit for Ang II induction of both GLUT1 and matrix protein synthesis. Finally, studies with ramipril in vivo and losartan in vitro have indicated that inhibition of angiotensin-
(For legend see next page.)

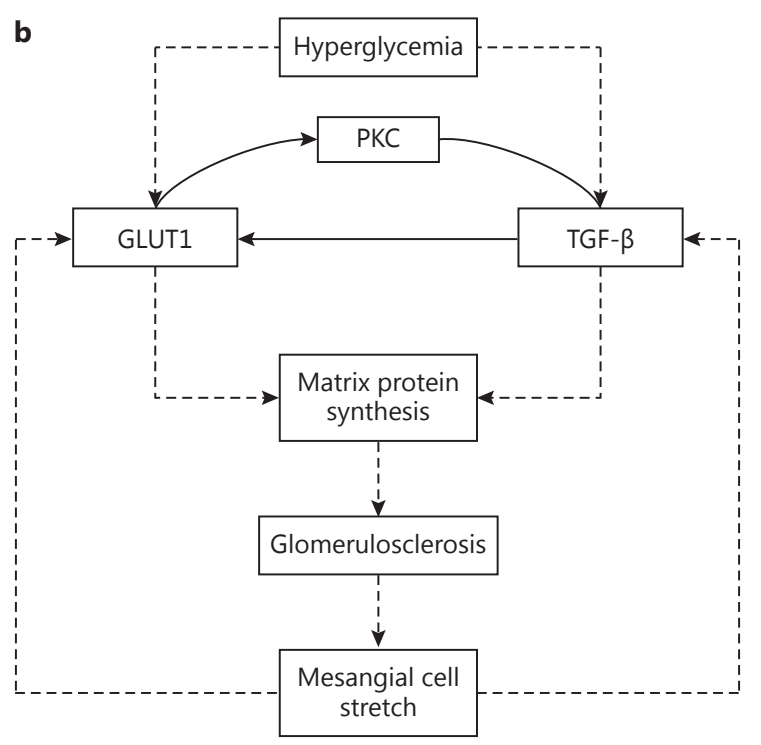

converting enzyme or angiotensin receptor-1 can suppress renal cortical GLUT1 [41] and mesangial glucose uptake [42], respectively. Ramipril reduced renal cortical angiotensin-converting enzyme activity and GLUT1 expression in diabetic, hypertensive rats [41], while losartan blunted the effects of high glucose on mesangial cell
42
Heilig/Deb/Abdul/Riaz/James/Salameh/ Nahman Jr. 


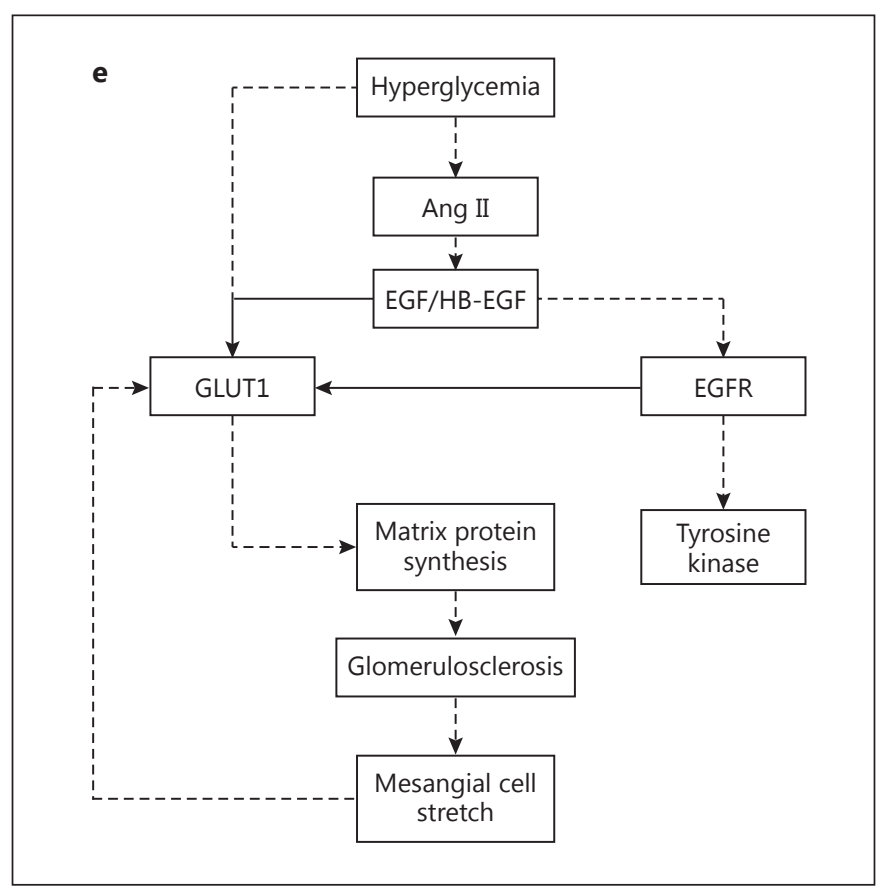

Fig. 1. Interactions of GLUT1 with six putative mediators of diabetic glomerulosclerosis. a Ang II. Hyperglycemia triggers Ang II production which induces GLUT1 expression and a GLUT1 amplification cascade. Progressive nephron loss from glomerulosclerosis also increases Ang II and GLUT1. Ang II and GLUT1 activation of PKC also promote glomerulosclerosis through TGF- $\beta$ dependent and -independent pathways. b TGF- $\beta$. A GLUT1 amplification loop is augmented by TGF- $\beta$ production which is in turn driven by hyperglycemia and GLUT1 activation of PKC. As glomerulosclerosis progresses, mesangial cell stretch also induces TGF- $\beta$ production. The increase in TGF- $\beta$ stimulates additional GLUT1 expression, invoking a GLUT1 amplification cascade. c CTGF. CTGF is activated by hyperglycemia, TGF- $\beta$ and an autoinduction cascade. In the presence of elevated glucose levels and

GLUT1, GLUT4, glucose uptake and fibronectin expression [42]. These data suggested potential protective effects of the drugs via these mechanisms against progression of diabetic nephropathy.

Taken together, the above studies demonstrate interactions between Ang II and GLUT1 through both metabolic and mechanical pathways. These events offer several examples of Ang II-driven processes that also stimulate GLUT1 synthesis, and thus trigger pro-sclerotic pathways resulting from increased glucose flux. In this model, GLUT1 may act to amplify the pro-fibrotic effects of Ang II, and thus serve as a potential regulator of the process.

GLUT1 Regulation of Diabetic

Glomerulosclerosis

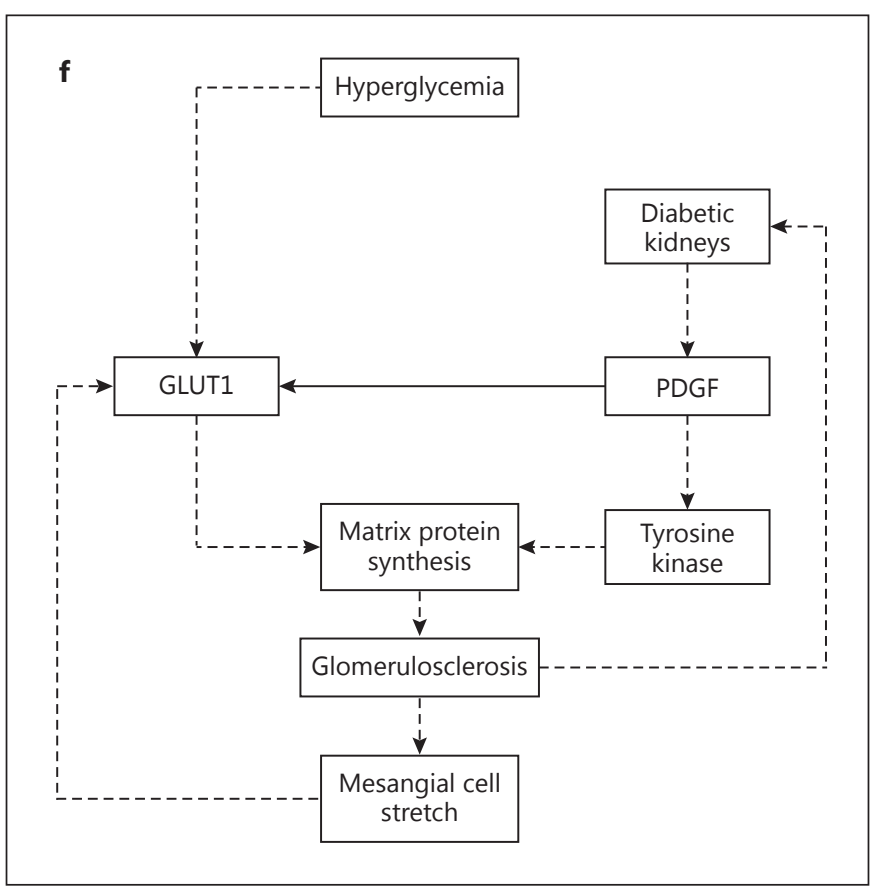

mesangial cell stretch, GLUT1 is activated and increases CTGF expression through TGF- $\beta$. d VEGF. Hyperglycemia and GLUT1 induce VEGF synthesis, which in turn activates a GLUT1 amplification loop. VEGF expression is also increased in glomerulosclerotic kidneys. e EGFR. Elevated glucose levels induce Ang II which, through G-protein-linked PKC activation, releases membranebound EGF and HB-EGF. These ligands bind the EGFR which activates tyrosine kinase and, along with free EGF and HB-EGF, triggers GLUT1 synthesis and the GLUT1 cascade. $f$ PDGF. PDGF expression is increased in diabetic glomerulosclerosis and triggers matrix protein synthesis through a tyrosine kinase-mediated pathway. PDGF also invokes a GLUT1 amplification loop by stimulating GLUT1 synthesis. Solid lines depict effects directly related to GLUT1 and a given mediator.

\section{Transforming Growth Factor $\beta$ (fig. 1b)}

TGF- $\beta$ is a pro-sclerotic cytokine directly involved in the pathogenesis of diabetic glomerulosclerosis and interstitial fibrosis [43]. TGF- $\beta$ activity is increased by a variety of stimuli [43], including hyperglycemia [44], DAG [32], Ang II [45], and cyclic mesangial cell stretch [46]. TGF- $\beta$ promotes glomerulosclerosis and interstitial fibrosis by stimulating matrix protein synthesis $[44,47]$ and inhibiting degradation [48].

TGF- $\beta$ signaling is mediated through a receptor complex that activates the Smad protein system [49]. Smad activation results in the assembly of a DNA-binding protein that can activate matrix protein synthesis, angiogenesis, and apoptosis [50]. TGF- $\beta$ may also signal through 
Smad-independent pathways and activate mitogen-activated protein kinase (MAPK) which can regulate cell proliferation [51].

TGF- $\beta$ activation of MAPK may trigger GLUT1 synthesis [52, 53]. In this regard, adipocytes mutated to constitutively express MAPK were shown to increase GLUT1 but not GLUT4 expression [53]. Transcriptional activator protein-1 may be a target of the MAPK system, and associate with the four, 12-O-tetradecanoylphorbol13-acetate-response elements present in the GLUT1 gene, and thus trigger GLUT1 synthesis [52].

MAPK induction of GLUT1 and the associated increase in glucose transport would be expected to increase DAG levels. In mesangial cells, TGF- $\beta$ activation of GLUT1 results in an increase in glucose flux [54] with induction of the DAG-PKC pathway [8]. The increase in PKC leads to further stimulation of TGF- $\beta$ synthesis [32] and may effectively define a DAG-mediated amplification loop between GLUT1 and TGF- $\beta$. In this regard, GLUT1 induction of TGF- $\beta$ was observed in whole glomeruli from transgenic mice overexpressing-GLUT1, but it remains unknown which cells in the glomerulus are responsible for this effect [10].

The development of glomerulosclerosis results in loss of filtration surface area, glomerular hypertension and mesangial cell stretch. Mesangial cell stretch activates both GLUT1 and TGF- $\beta[11,46]$ and may reactivate or bolster the above amplification cycle. Taken together, TGF- $\beta$ may trigger GLUT1 through MAPK and/or mesangial cell stretch. GLUT1 activation, through increased glucose flux in turn drives additional TGF- $\beta$ synthesis via DAG and PKC. The pro-sclerotic effects of TGF- $\beta$ and their subsequent amplification by GLUT1-mediated pathways may thus contribute to the development and progression of glomerulosclerosis.

\section{Connective Tissue Growth Factor (fig. 1c)}

CTGF is a pro-sclerotic cytokine and a member of the CCN gene family [55]. CTGF is induced by TGF- $\beta$ and promotes matrix protein synthesis $[56,57]$. In this regard, it is an important mediator of matrix accumulation in glomerulosclerosis [58]. Gene and protein expression of CTGF are increased in fibrotic tissues [55] and glomerular CTGF gene expression has been shown to be increased in diabetic rats [58]. Mediators of CTGF gene or protein expression include TGF- $\beta$ [57], elevated glucose [58, 59], mechanical strain [58] and an autoinduction pathway [58].

Increased glucose availability increases mesangial cell CTGF via a TGF- $\beta$-dependent pathway [60]. This implies that upregulation of GLUT1, through an increase in glucose flux, may result in an increase in CTGF by stimulating TGF- $\beta$, suggesting a potential role for GLUT1 in this activation loop. The mechanism by which mechanical strain may stimulate CTGF is unclear; however, GLUT1 induction and/or increases in TGF- $\beta$ may underlie the process $[11,46]$. These data suggest a potential amplification loop between GLUT1 and CTGF via TGF- $\beta$ dependent pathways, but the relationship remains to be defined.

\section{Vascular Endothelial Growth Factor (fig. 1d)}

VEGF (same as VEGF-A) is part of a family of VEGF proteins which includes VEGF-A, -B, -C, -D and placental-derived growth factor [61]. VEGF promotes angiogenesis, is highly expressed by podocytes, and is important in glomerular development [61-63]. VEGF is expressed in the adult kidney and has a paracrine role in glomerular endothelial cell signaling and fenestration formation $[61,64]$. VEGF signaling in diabetic nephropathy appears via the VEGF receptor type 2 [61, 65-67].

VEGF may contribute to the pathogenesis of diabetic nephropathy [68-73]. In experimental diabetes, VEGF expression is increased in some studies [68], while in some others it is not $[74,75]$, or demonstrated a protective effect by deletion of VEGF-A from podocytes [76]. Treatment with antibody to VEGF prevented diabetesinduced increases in glomerular volume and albuminuria [69]. Using a nitric oxide (NO) knockout mouse, Nakagawa [70] induced diabetes and showed the development of diabetic glomerulosclerosis with elevated VEGF expression. In these studies, it was proposed that VEGF may promote the development of diabetic nephropathy through an 'uncoupling' with NO [70]. In this model, VEGF triggers NO release, and acts with $\mathrm{NO}$ as a trophic factor for the endothelium [70]. NO derived from endothelial cells prevents endothelial cell and smooth muscle proliferation, and macrophage infiltration [70]. In the knockout mice, unmitigated VEGF was associated with the development of glomerulopathy consistent with diabetic glomerulosclerosis [70, 77]. Taken together, these data suggest a role for VEGF in promoting the development of diabetic nephropathy, and imply a link with endothelial NO production [70, 71].

GLUT1 overexpression in transduced mesangial cells has been associated with increased VEGF gene expression [78]. More recently in nephron-deficient transgenic Fvb mice with glomerulosclerosis, mesangial cell and glomerular VEGF expression was increased [11]. Furthermore, in cultured mesangial cells cyclic stretch induced an in-
Heilig/Deb/Abdul/Riaz/James/Salameh/ Nahman Jr. 
crease in GLUT1 expression which preceded an elevation in VEGF [11]. When these cells were treated with VEGF, an increase in both GLUT1 and glucose uptake was demonstrated, indicating that VEGF is a potent stimulus to GLUT1 synthesis. VEGF also triggered matrix protein synthesis in mesangial cells, which was suppressed by an antisense sequence to GLUT1 [11]. Data in podocytes are consistent with the finding of VEGF-induced matrix expression $[79,80]$. These data provide compelling evidence for bidirectional stimulation between GLUT1 and VEGF, with VEGF induction of matrix protein synthesis dependent, at least in part on GLUT1 expression. Taken together, these studies, and the work of others, suggest a pro-sclerotic role for VEGF in diabetic nephropathy, and indicate that GLUT1 may regulate and/or augment some facets of VEGF-induced matrix protein synthesis in this disease.

\section{Epidermal Growth Factor and the EGFR (fig. 1e)}

The EGFR is a tyrosine kinase-linked transmembrane glycoprotein influencing proliferation, differentiation and tumorigenesis [81]. In addition, the EGFR has been shown to regulate cardiac hypertrophy and vascular smooth muscle tone $[82,83]$. In diabetes, EGFR signaling may modulate vascular wall thickening and the microvascular complications of the disease [82]. In this regard, vascular wall remodeling in diabetic mice was improved with tyrosine kinase inhibition [82].

The EGFR may be activated by several ligands, including epidermal growth factor (EGF) and heparin-bound EGF (HB-EGF) [81]. HB-EGF is released from the cell surface by enzymatic cleavage [81]. Ligand binding to Gprotein-linked receptors can also result in EGFR-mediated responses by triggering the cleavage of surface-bound EGFR ligands like HB-EGF [81] In this regard, Ang II engagement of the AT1 receptor has been shown to induce EGFR responses via this mechanism (see Angiotensin II, above) [83].

Using cultured mesangial cells, Nose et al. [35] demonstrated Ang II induction of GLUT1. The process was partially attenuated by an EGFR inhibitor, indicating that Ang II activation of GLUT1 expression was in part mediated via the EGFR [35]. This observation is consistent with transactivation of the EGFR by Ang II with downstream induction of tyrosine kinase-mediated pathways [83]. The authors also showed that EGF and HB-EGF triggered GLUT1 synthesis [35]. Taken together, these studies indicate a role for the EGFR in mediating Ang II induction of GLUT1, and demonstrate that activation of the EGFR with EGF and HB-EGF may activate GLUT1 synthesis independent of Ang II. These observations suggest that mediators acting via the EGFR may induce GLUT1 synthesis and provide additional pathways for GLUT1 induction of pro-sclerotic events in diabetic nephropathy.

\section{Platelet-Derived Growth Factor (fig. 1f)}

Platelet-derived growth factor (PDGF) is a glycoprotein dimer mediating its effect via two related tyrosine kinase PDGFR $[7,84]$. PDGF is expressed in mesangial cells and mediates cellular proliferation and matrix protein deposition [84]. PDGF and PDGFR expression were increased in experimental diabetic nephropathy [85] and Langham et al. [85] demonstrated increased PDGF expression in renal biopsies from diabetic patients. Finally, Lassila et al. [86], using an animal model of accelerated diabetic nephropathy, showed increased renal PDGF expression, and increased glomerular and tubulointerstitial matrix protein accumulation in diabetic animals. These changes were attenuated in diabetic mice treated with a tyrosine kinase inhibitor [86]. These studies support a role for PDGF in the pathogenesis of diabetic glomerulosclerosis, and suggest the effects of the growth factor may be inhibited by tyrosine kinase blockade.

GLUT1 may potentiate the effect of PDGF on the kidney in diabetes. In this regard, the GLUT1 promoter region has specific PDGF response elements [21], and under the influence of PDGF, GLUT1 has been shown to translocate to the cell membrane of adipocytes, where it increased glucose uptake [87]. Finally, PDGF has been shown to stimulate GLUT1 synthesis and glucose transport in skeletal muscle from transgenic mice overexpressing the PDGFR [88]. These data suggest a model whereby PDGF may stimulate GLUT1 expression and glucose utilization, triggering GLUT1-mediated pro-sclerotic cascades associated with the development of diabetic glomerulosclerosis.

\section{GLUT1 as a Facilitator of the Pro-Sclerotic Mediators of Diabetic Glomerulosclerosis}

GLUT1 promotes the development of glomerular disease resembling diabetic glomerulosclerosis via the cellular uptake and utilization of glucose [10]. In diabetes, GLUT1-mediated utilization of glucose activates at least 4 pro-sclerotic pathways, all of which may facilitate the development of glomerulosclerosis. The loss of filtration surface area from glomerulosclerosis leads to glomerular hypertension and mesangial cell stretch. Mesangial 


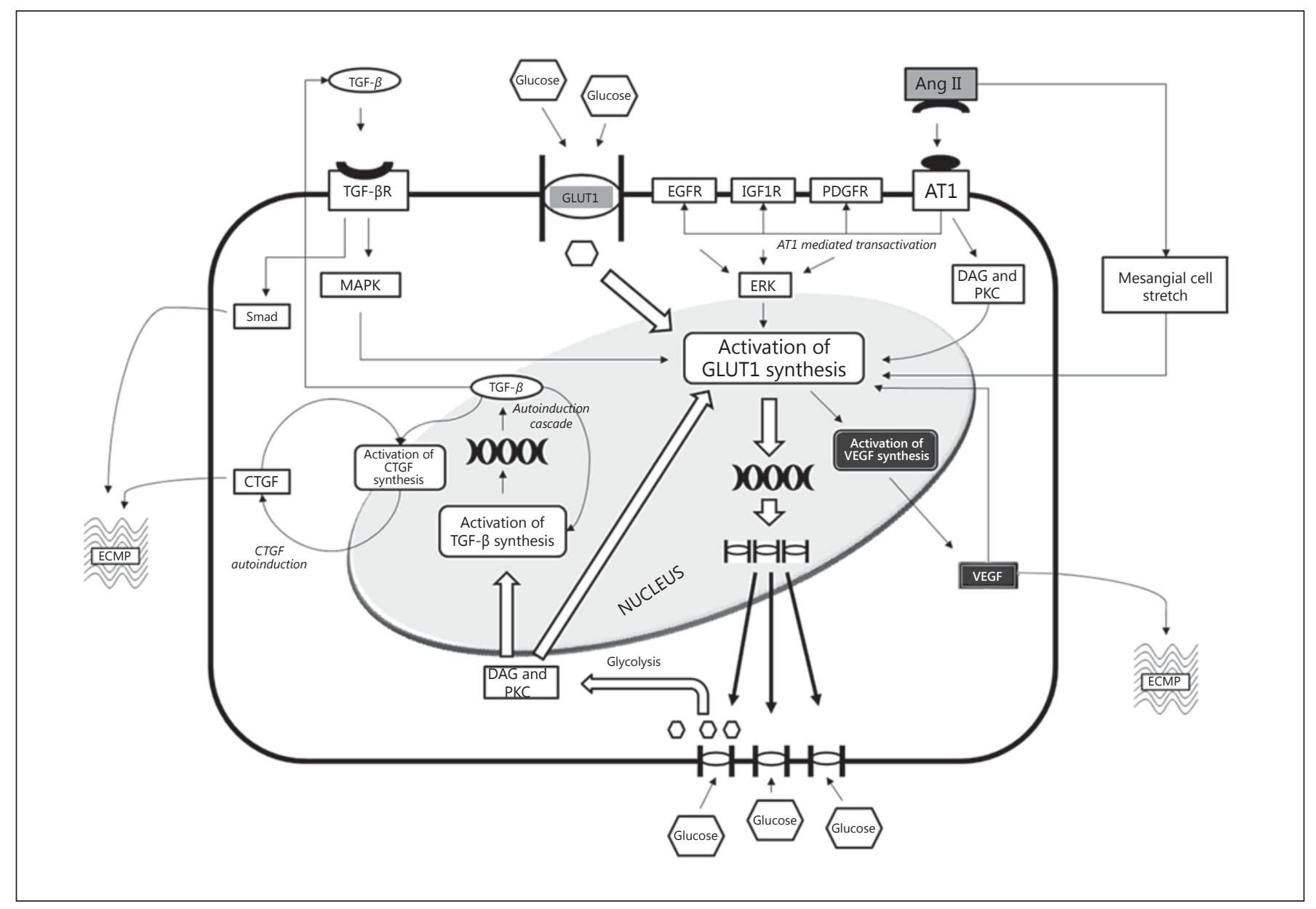

Fig. 2. Summary of pathways interacting with GLUT1. GLUT1 facilitates the movement of glucose into the cell (top and bottom) and triggers GLUT1 synthesis (top). Activation of GLUT1 synthesis is also associated with an increase in VEGF and extracellular matrix protein (ECMP) synthesis (lower right). GLUT1-mediated intracellular transport of glucose increases intracellular glucose availability leading to glucose metabolism via glycolysis, with generation of DAG and activation of PKC, which stimulates TGF- $\beta$, as well as more GLUT1 (bottom left). TGF- $\beta$-mediated events in-

stretch triggers GLUT1 synthesis and expression, effectively defining a GLUT1 self-expression loop that promotes glomerulosclerosis. Hyperglycemia also upregulates GLUT1 expression, initiating and constantly stimulating this amplification cascade.

Cytokines and growth factors promoting the development of glomerulosclerosis may activate the GLUT1 amplification cascade at numerous levels, thus invoking this parallel pro-sclerotic pathway. In many cases, the recruitment of GLUT1-mediated pathways may intensify or augment fibrotic events directly stimulated by a given cy- clude an autoinduction cascade, activation of the highly pro-fibrotic cytokine CTGF, and engagement of the TGF- $\beta$ receptor, triggering more GLUT1 synthesis through MAPK, as well as ECMP synthesis via Smads. Ang II (top right) induces mesangial cell strain and GLUT1 synthesis. In addition, Ang II engagement of the AT1 receptor triggers DAG/PKC, and additional GLUT1 synthesis. AT1 binding also is associated with transactivation of the EGFR, IGF-1R and PDGFR, all of which may trigger ERK and more GLUT1 synthesis. tokine or growth factor, making GLUT1 a strong co-mediator of diabetic glomerulosclerosis in this setting. This stance is supported in recently developed transgenic mouse models in which diabetic glomerulosclerosis was the pathologic result in nondiabetic mice overexpressing GLUT1, and raises interesting questions about a more global role for GLUT1 in the pathogenesis of glomerulosclerosis (summarized in fig. 2).

Finally, the role of GLUT1 as a mediator of glomerulosclerosis, and as a potential therapeutic target, will be further elucidated as pharmacologic inhibitors of GLUT1 
are developed. In this regard, naturally occurring flavones as well as synthetic tyrphostins have been recently shown to inhibit GLUT1 through distinct mechanisms [89]. Continued work in this area will likely generate compounds of therapeutic potential in the treatment of GLUT1-driven glomerulosclerosis.

In summary, GLUT1 may act in concert with cytokines and growth factors, in some cases in positive feedback fashion, to mediate development of diabetic glomerulosclerosis. Defining the role of GLUT1 in facilitating these pro-sclerotic events may give new insights for the therapy and management of diabetic glomerulosclerosis, and provide strategies for slowing the development and progression of this disease. Recent findings of potential roles for MGF and mTOR in GLUT1-mediated extracellular matrix production provide important avenues for future investigation in this field, as do the findings of potentially important therapeutic roles for angiotensinconverting enzyme inhibitors and angiotensin receptor blockers in suppression of diabetes-induced GLUT1 and glucose uptake in the kidney.

\section{Acknowledgements}

Supported by Juvenile Diabetes Research Foundation grant 1-2004-698 (C.W.H.), American Diabetes Association grant 7-02RA-34 (C.W.H.), Dialysis Clinics Inc. grants C-2957 \& C-3427 (C.W.H.), and the Augusta Biomedical Research Corporation (N.S.N.).

\section{Disclosure Statement}

The authors have no conflicts of interest to disclose.

\section{References}

1 USRDS: USRDS 2010 Annual Data Report. Bethesda, NIH, NIDDK, 2010.

-2 Mauer SM, Steffes MW, Ellis EN, Sutherland DE, Brown DM, Goetz FC: Structural-functional relationships in diabetic nephropathy. J Clin Invest 1984;74:1143-1155.

3 Ibrahim HN, Hostetter TH: Diabetic nephropathy. J Am Soc Nephrol 1997;8:487493.

4 Diabetes Control and Complications Trial Research Group (DCCT): The effect of intensive treatment of diabetes on the development and progression of long-term complications in insulin-dependent diabetes mellitus. N Engl J Med 1993;329:977-986.

5 Stratton IM, Adler AI, Neil HA, Matthews DR, Manley SE, Cull CA, Hadden D, Turner RC, Holman RR: Association of glycaemia with macrovascular and microvascular complications of type 2 diabetes (UKPDS 35): prospective observational study. BMJ 2000;321: 405-412.

-6 Bilous RW, Mauer SM, Sutherland DE, Najarian JS, Goetz FC, Steffes MW: The effects of pancreas transplantation on the glomerular structure of renal allografts in patients with insulin-dependent diabetes. N Engl J Med 1989;321:80-85.

7 Chiarelli F, Gaspari S, Marcovecchio ML: Role of growth factors in diabetic kidney disease. Horm Metab Res 2009;41:585-593.

8 Heilig CW, Concepcion LA, Riser BL, Freytag SO, Zhu M, Cortes P: Overexpression of glucose transporters in rat mesangial cells cultured in a normal glucose milieu mimics the diabetic phenotype. J Clin Invest 1995;96: 1802-1814 $\checkmark 9$ Vesely ED, Heilig CW, Brosius FC 3rd: GLUT1-induced cFLIP expression promotes proliferation and prevents apoptosis in vascular smooth muscle cells. Am J Physiol Cell Physiol 2009;297:C759-C765.

10 Wang YHK, Saunders T, Minto A, Deb DK, Chang A, Brosius F, Monteiro C, Heilig CW: Transgenic overexpression of GLUT1 in mouse glomeruli produces renal disease resembling diabetic glomerulosclerosis. Am J Physiol Renal Physiol 2010;299:F99-F111.

11 Wang $\mathrm{Y}$, Heilig KO, Minto AW, Chen S, Xiang M, Dean DA, Geiger RC, Chang A, Pravtcheva DD, Schlimme M, Deb DK, Heilig CW: Nephron-deficient Fvb mice develop rapidly progressive renal failure and heavy albuminuria involving excess glomerular GLUT1 and VEGF. Lab Invest 2010;90:8397.

12 Heilig K, Chen S, Xiang M, Brosius F, Heilig C: Overexpression of GLUT1 in glomeruli produces features of diabetic nephropathy in mice (abstract). J Am Soc Nephrol 2004;15: 263A.

13 Heilig CW, Kreisberg JI, Freytag S, Murakami T, Ebina Y, Guo L, Heilig K, Loberg R, Qu X, Jin Y, Henry D, Brosius FC 3rd: Antisense GLUT-1 protects mesangial cells from glucose induction of GLUT-1 and fibronectin expression. Am J Physiol Renal Physiol 2001; 280:F657-F666.

14 Chen SHK, Brosius F 3rd, Heilig C: Diabetes increases glomerular GLUT1, and antisenseGLUT1 protects against diabetic glomerulosclerosis. J Am Soc Nephrol 2003;14:14A.
15 Manolescu AR, Witkowska K, Kinnaird A, Cessford T, Cheeseman C: Facilitated hexose transporters: new perspectives on form and function. Physiology (Bethesda) 2007;22: 234-240.

16 Brosius FC 3rd, Briggs JP, Marcus RG, BaracNieto M, Charron MJ: Insulin-responsive glucose transporter expression in renal microvessels and glomeruli. Kidney Int 1992;42: 1086-1092.

17 Heilig C, Zaloga C, Lee M, Zhao X, Riser B, Brosius F, Cortes P: Immunogold localization of high-affinity glucose transporter isoforms in normal rat kidney. Lab Invest 1995;73:674684.

18 Heilig CW, Liu Y, England RL, Freytag SO, Gilbert JD, Heilig KO, Zhu M, Concepcion LA, Brosius FC 3rd: D-Glucose stimulates mesangial cell GLUT1 expression and basal and IGF-1-sensitive glucose uptake in rat mesangial cells: implications for diabetic nephropathy. Diabetes 1997;46:1030-1039.

19 Henry DN, Busik JV, Brosius FC 3rd, Heilig CW: Glucose transporters control gene expression of aldose reductase, $\mathrm{PKCa}$, and GLUT1 in mesangial cells in vitro. Am J Physiol 1999;277:F97-F104.

20 Heilig CW, Brosius FC 3rd, Cunningham C: Role for GLUT1 in diabetic glomerulosclerosis. Expert Rev Mol Med 2006;8:1-18.

21 Murakami T, Nishiyama T, Shirotani T, Shinohara, Y, Kan M, Ishii K, Kanai F, Nakazuru S, Ebina Y: Identification of two enhancer elements in the gene encoding the type 1 glucose transporter from the mouse which are responsive to serum, growth factor, and oncogenes. J Biol Chem 1992;267:9300-9306. 
22 Hwang DY, Ismail-Beigi F: Control of Glut1 promoter activity under basal conditions and in response to hyperosmolarity: role of Sp1. Am J Physiol Cell Physiol 2006;290:C337-C344.

23 Behrooz A, Ismail-Beigi F: Dual control of glut1 glucose transporter gene expression by hypoxia and by inhibition of oxidative phosphorylation. J Biol Chem 1997;272:55555562.

24 Xiang MHK, Nahman N, Heilig C: Mechanogrowth factor regulation by diabetes and GLUT1 in glomeruli (abstract). J Am Soc Nephrol 2010;21:167A.

25 Xiang MHK, James LR, Panni J, Nahman NS Jr, Heilig CW: Mechano-growth factor induces the mesangial cell GLUT1 glucose transport system. J Am Soc Nephrol 2011;22:471A.

-26 Buller CL, Heilig CW, Brosius FC 3rd: GLUT1 enhances mTOR activity independently of TSC2 and AMPK. Am J Physiol Renal Physiol 2011;301:F588-F596.

-27 Higuchi S, Ohtsu H, Suzuki H, Shirai H, Frank GD, Eguchi S: Angiotensin II signal transduction through the AT1 receptor: novel insights into mechanisms and pathophysiology. Clin Sci (Lond) 2007;112:417-428.

28 Carey RM, Siragy HM: The intrarenal reninangiotensin system and diabetic nephropathy. Trends Endocrinol Metab 2003;14:274281.

-29 Gnudi L, Thomas SM, Viberti G: Mechanical forces in diabetic kidney disease: a trigger for impaired glucose metabolism. J Am Soc Nephrol 2007;18:2226-2232.

- 30 Singh R, Singh AK, Alavi N, Leehey DJ: Mechanism of increased angiotensin II levels in glomerular mesangial cells cultured in high glucose. J Am Soc Nephrol 2003;14:873-880.

- 31 Zatz R, Dunn BR, Meyer TW, Anderson S, Rennke HG, Brenner BM: Prevention of diabetic glomerulopathy by pharmacological amelioration of glomerular capillary hypertension. J Clin Invest 1986;77:1925-1930.

- 32 Koya D, Jirousek MR, Lin YW, Ishii H, Kuboki K, King GL: Characterization of protein kinase $C \beta$-isoform activation on the gene expression of transforming growth factor- $\beta$, extracellular matrix components, and prostanoids in the glomeruli of diabetic rats. J Clin Invest 1997;100:115-126.

-33 Rovin BH, Yoshiumura T, Tan L: Cytokineinduced production of monocyte chemoattractant protein- 1 by cultured human mesangial cells. J Immunol 1992;148:2148-2153.

- 34 Weigert C, Brodbeck K, Brosius FC 3rd, Huber M, Lehmann R, Friess U, Facchin S, Aulwurm S, Haring HU, Schleicher ED, Heilig CW: Evidence for a novel TGF- $\beta_{1}$-independent mechanism of fibronectin production in mesangial cells overexpressing glucose transporters. Diabetes 2003;52:527-535.

35 Nose A, Mori Y, Uchiyama-Tanaka Y, et al: Regulation of glucose transporter (GLUT1) gene expression by angiotensin II in mesangial cells: involvement of HB-EGF and EGF receptor transactivation. Hypertens Res 2003; 26:67-73.
36 Di Simone N, Di Nicuolo F, Marzioni D, et al: Resistin modulates glucose uptake and glucose transporter-1 (GLUT-1) expression in trophoblast cells. J Cell Mol Med 2009;13: 388-397.

37 Oppermann MF, Castrop H, Mizel D, Heilig K, Heilig C, Schnermann J: Glomerular hypertension and hyperfiltration in young fvb. ROP Os/+ mice. FASEB J 2007;21:595.28.

38 Pugliese G, Pricci F, Barsotti P, Iacobini C, Ricci C, Oddi G, Romeo G, Leto G, Marano G, Sorcini M, Sabbatini M, Fuiano G, Di Mario U, Pugliese F: Development of diabetic nephropathy in the Milan normotensive strain, but not in the Milan hypertensive strain: possible permissive role of hemodynamics. Kidney Int 2005;67:1440-1452.

39 Ricci C, Iacobini C, Oddi G, Amadio L, Menini S, Rastaldi MP, Frasheri A, Pricci F, Pugliese F, Pugliese G: Role of TGF- $\beta /$ GLUT1 axis in susceptibility versus resistance to diabetic glomerulopathy in the Milan rat model. Nephrol Dial Transplant 2006;21:1514-1524.

40 Forbes JM, Fukami K, Cooper ME: Diabetic nephropathy: where hemodynamics meets metabolism. Exp Clin Endocrinol Diabetes 2007;115:69-84

41 Souza MS, Machado UF, Okamoto M, et al: Reduced cortical renal GLUT1 expression induced by angiotensin-converting enzyme inhibition in diabetic spontaneously hypertensive rats. Braz J Med Biol Res 2008;41:960968.

42 Arnoni CP, Lima C, Cristovam PC, Maquigussa E, Vidotti DB, Boim MA: Regulation of glucose uptake in mesangial cells stimulated by high glucose: role of angiotensin II and insulin. Exp Biol Med (Maywood) 2009;234: 1095-1101.

43 Chen S, Jim B, Ziyadeh FN: Diabetic nephropathy and transforming growth factor- $\beta$ : transforming our view of glomerulosclerosis and fibrosis build-up. Semin Nephrol 2003; 23:532-543.

44 Ziyadeh FN, Sharma K, Ericksen M, Wolf G: Stimulation of collagen gene expression and protein synthesis in murine mesangial cells by high glucose is mediated by autocrine activation of transforming growth factor- $\beta$. J Clin Invest 1994;93:536-542.

45 Wolf G, Ziyadeh FN: The role of angiotensin II in diabetic nephropathy: emphasis on nonhemodynamic mechanisms. Am J Kidney Dis 1997;29:153-163.

46 Riser BL, Cortes P, Heilig C, et al: Cyclic stretching force selectively up-regulates transforming growth factor- $\beta$ isoforms in cultured rat mesangial cells. Am J Pathol 1996; 148:1915-1923.

47 Isaka Y, Fujiwara Y, Ueda N, Kaneda Y, Kamada T, Imai E: Glomerulosclerosis induced by in vivo transfection of transforming growth factor- $\beta$ or platelet-derived growth factor gene into the rat kidney. J Clin Invest 1993;92:2597-2601.
48 Border WA, Noble NA: Transforming growth factor- $\beta$ in tissue fibrosis. N Engl J Med 1994; 331:1286-1292.

49 Massague J, Wotton D: Transcriptional control by the TGF- $\beta /$ Smad signaling system. EMBO J 2000;19:1745-1754.

50 Moustakas A, Heldin $\mathrm{CH}$ : The regulation of TGF- $\beta$ signal transduction. Development 2009;136:3699-3714

51 Wang W, Koka V, Lan HY: Transforming growth factor- $\beta$ and Smad signalling in kidney diseases. Nephrology (Carlton) 2005;10: 48-56.

52 Fujishiro M, Gotoh Y, Katagiri $\mathrm{H}$, et al: MKK6/3 and p38 MAPK pathway activation is not necessary for insulin-induced glucose uptake but regulates glucose transporter expression. J Biol Chem 2001;276:19800-19806.

53 Yamamoto Y, Yoshimasa Y, Koh M, Suga J, Masuzaki H, Ogawa Y, Hosoda K, Nishimura $\mathrm{H}$, Watanabe Y, Inoue G, Nakao K: Constitutively active mitogen-activated protein kinase kinase increases GLUT1 expression and recruits both GLUT1 and GLUT4 at the cell surface in 3T3-L1 adipocytes. Diabetes 2000;49: $332-339$

54 Inoki K, Haneda M, Maeda S, Koya D, Kikkawa R: TGF- $\beta_{1}$ stimulates glucose uptake by enhancing GLUT1 expression in mesangial cells. Kidney Int 1999;55:1704-1712.

55 Qi W, Chen X, Poronnik P, Pollock CA: Transforming growth factor- $\beta /$ connective tissue growth factor axis in the kidney. Int J Biochem Cell Biol 2008;40:9-13.

56 Twigg SM, Chen MM, Joly AH, Chakrapani SD, Tsubaki J, Kim HS, Oh Y, Rosenfeld RG: Advanced glycosylation end products up-regulate connective tissue growth factor (insulinlike growth factor-binding protein-related protein 2) in human fibroblasts: a potential mechanism for expansion of extracellular matrix in diabetes mellitus. Endocrinology 2001; 142:1760-1769.

57 Qi W, Twigg S, Chen X, Polhill TS, Poronnik $\mathrm{P}$, Gilbert RE, Pollock CA: Integrated actions of transforming growth factor- $\beta_{1}$ and connective tissue growth factor in renal fibrosis. Am J Physiol Renal Physiol 2005;288:F800-F809.

- 58 Riser BL, Denichilo M, Cortes P, Baker C, Grondin JM, Yee J, Narins RG: Regulation of connective tissue growth factor activity in cultured rat mesangial cells and its expression in experimental diabetic glomerulosclerosis. J Am Soc Nephrol 2000;11:25-38.

59 Murphy M, Crean J, Brazil DP, Sadlier D, Martin F, Godson C: Regulation and consequences of differential gene expression in diabetic kidney disease. Biochem Soc Trans 2008:36:941-945.

60 Murphy M, Godson C, Cannon S, Kato S, Mackenzie HS, Martin F, Brady HR: Suppression subtractive hybridization identifies high glucose levels as a stimulus for expression of connective tissue growth factor and other genes in human mesangial cells. J Biol Chem 1999;274:5830-5834. 
61 Foster RR: The importance of cellular VEGF bioactivity in the development of glomerular disease. Nephron Exp Nephrol 2009;113:e8e15.

62 Eremina V, Sood M, Haigh J, Nagy A, Lajoie G, Ferrara N, Gerber HP, Kikkawa Y, Miner $\mathrm{JH}$, Quaggin SE: Glomerular-specific alterations of VEGF-A expression lead to distinct congenital and acquired renal diseases. J Clin Invest 2003;111:707-716.

-63 Eremina V, Quaggin SE: The role of VEGF-A in glomerular development and function. Curr Opin Nephrol Hypertens 2004;13:9-15.

64 Sison K, Eremina V, Baelde H, Min W, Hirashima M, Fantus IG, Quaggin SE: Glomerular structure and function require paracrine, not autocrine, VEGF-VEGFR-2 signaling. J Am Soc Nephrol 21:1691-1701.

-65 Villegas G, Lange-Sperandio B, Tufro A: Autocrine and paracrine functions of vascular endothelial growth factor in renal tubular epithelial cells. Kidney Int 2005;67:449-457.

-66 Guan F, Villegas G, Teichman J, Mundel P, Tufro A: Autocrine VEGF-A system in podocytes regulates podocin and its interaction with CD2AP. Am J Physiol Renal Physiol 2006;291:F422-F428.

67 Bertuccio C, Veron D, Aggarwal PK, Holzman L, Tufro A: Vascular endothelial growth factor receptor-2 direct interaction with nephrin links VEGF-A signals to actin in kidney podocytes. J Biol Chem 286:39933-39944.

- 68 Cooper ME, Vranes D, Youssef S, Stacker SA, Cox AJ, Rizkalla Casley DJ, Bach LA, Kelly DJ, Gilbert RE: Increased renal expression of vascular endothelial growth factor and its receptor VEGFR-2 in experimental diabetes. Diabetes 1999;48:2229-2239.

-69 Flyvbjerg A, Dagnaes-Hansen F, De Vriese AS, Schrijvers BF, Tilton RG, Rasch R: Amelioration of long-term renal changes in obese type 2 diabetic mice by a neutralizing vascular endothelial growth factor antibody. Diabetes 2002;51:3090-3094.

70 Nakagawa T: Uncoupling of the VEGF-endothelial nitric oxide axis in diabetic nephropathy: an explanation for the paradoxical effects of VEGF in renal disease. Am J Physiol Renal Physiol 2007;292:F1665-F1672.

71 Ziyadeh FN, Wolf G: Pathogenesis of the podocytopathy and proteinuria in diabetic glomerulopathy. Curr Diabetes Rev 2008;4: $39-45$.
72 De Vriese AS, Tilton RG, Elger M, Stephan CC, Kriz W, Lameire NH: Antibodies against vascular endothelial growth factor improve early renal dysfunction in experimental diabetes. J Am Soc Nephrol 2001;12:993-1000.

73 Sung SH, Ziyadeh FN, Wang A, Pyagay PE, Kanwar YS, Chen S: Blockade of vascular endothelial growth factor signaling ameliorates diabetic albuminuria in mice. J Am Soc Nephrol 2006;17:3093-3104.

74 Shulman K, Rosen S, Tognazzi K, Manseau EJ, Brown LF: Expression of vascular permeability factor (VPF/VEGF) is altered in many glomerular diseases. J Am Soc Nephrol 1996; 7:661-666.

75 Lindenmeyer MT, Kretzler M, Boucherot A, Berra S, Yasuda Y, Henger A, Eichinger F, Gaiser S, Schmid H, Rastaldi MP, Schrier RW, Schlondorff D, Cohen CD: Interstitial vascular rarefaction and reduced VEGF-A expression in human diabetic nephropathy. J Am Soc Nephrol 2007;18:1765-1776.

76 Sivaskandarajah GA, Jeansson M, Maezawa Y, Eremina V, Baelde HJ, Quaggin SE: VEGFA protects the glomerular microvasculature in diabetes. Diabetes 61:2958-2966.

77 Veron D, Reidy KJ, Bertuccio C, Teichman J, Villegas G, Jimenez J, Shen W, Kopp JB, Thomas DB, Tufro A: Overexpression of VEGF-A in podocytes of adult mice causes glomerular disease. Kidney Int 2010;77:989999.

78 Pfafflin A, Brodbeck K, Heilig CW, Haring HU, Schleicher ED, Weigert C: Increased glucose uptake and metabolism in mesangial cells overexpressing glucose transporter 1 increases interleukin- 6 and vascular endothelial growth factor production: role of AP-1 and HIF-1a. Cell Physiol Biochem 2006;18:199210.

79 Chen S, Kasama Y, Lee JS, Jim B, Marin M, Ziyadeh FN: Podocyte-derived vascular endothelial growth factor mediates the stimulation of $\alpha 3$ (IV) collagen production by transforming growth factor- $\beta_{1}$ in mouse podocytes. Diabetes 2004;53:2939-2949.
80 Chen S, Lee JS, Iglesias-de la Cruz MC, Wang A, Izquierdo-Lahuerta A, Gandhi NK, Danesh FR, Wolf G, Ziyadeh FN: Angiotensin II stimulates $\alpha 3$ (IV) collagen production in mouse podocytes via TGF- $\beta$ and VEGF signalling: implications for diabetic glomerulopathy. Nephrol Dial Transplant 2005;20:1320-1328.

81 Schneider MR, Wolf E: The epidermal growth factor receptor ligands at a glance. J Cell Physiol 2009;218:460-466.

82 Matrougui K: Diabetes and microvascular pathophysiology: role of epidermal growth factor receptor tyrosine kinase. Diabetes Metab Res Rev 2010;26:13-16.

83 Smith NJ, Chan HW, Osborne JE, Thomas WG, Hannan RD: Hijacking epidermal growth factor receptors by angiotensin II: new possibilities for understanding and treating cardiac hypertrophy. Cell Mol Life Sci 2004;61:2695-2703.

84 Alvarez RH, Kantarjian HM, Cortes JE: Biology of platelet-derived growth factor and its involvement in disease. Mayo Clin Proc 2006; 81:1241-1257.

85 Langham RG, Kelly DJ, Maguire J, Dowling JP, Gilbert RE, Thomson NM: Over-expression of platelet-derived growth factor in human diabetic nephropathy. Nephrol Dial Transplant 2003;18:1392-1396.

86 Lassila M, Jandeleit-Dahm K, Seah KK, Smith CM, Calkin AC, Allen TJ, Cooper, ME: Imatinib attenuates diabetic nephropathy in apolipoprotein E-knockout mice. J Am Soc Nephrol 2005;16:363-373.

87 Wang L, Hayashi H, Ebina Y: Transient effect of platelet-derived growth factor on GLUT4 translocation in 3T3-L1 adipocytes. J Biol Chem 1999;274:19246-19253.

88 Yuasa T, Kakuhata R, Kishi K, Obata T, Shinohara Y, Bando Y, Izumi K, Kajiura F, Matsumoto M, Ebina Y: Platelet-derived growth factor stimulates glucose transport in skeletal muscles of transgenic mice specifically expressing platelet-derived growth factor receptor in the muscle, but it does not affect blood glucose levels. Diabetes 2004;53:2776-2786.

- 89 Perez A, Ojeda P, Ojeda L, Ojeda L, Salas M, Rivas CI, Vera JC, Reyes AM: Hexose transporter GLUT1 harbors several distinct regulatory binding sites for flavones and tyrphostins. Biochemistry 2011;50:8834-8845. 